M. Bartmański, B. Świeczko-Żurek

Gdansk University of Technology, Department of Materials Science and Welding Engineering, Narutowicza 11/12, 80-233 Gdańsk, Poland

\title{
PROJECT OF HIP JOINT ENDOPROSTHESIS FOR AN INDIVIDUAL PATIENT WITH MATERIALS SELECTION
}

\section{ABSTRACT}

Nowadays the joint replacement orthopaedic surgery is most frequently performed surgery associated with the damage of the join surface. The implantation is mainly placed in hip and knee area. This work includes the hip replacement design, based on the patient's medical records, the description of creation process and materials used for individual components.

Keywords: joint replacement, endoprosthesis, biomaterials

\section{INTRODUCTION}

The attempts of hip joints replacement dates back centuries, but the greatest development occurred in the second half of the twentieth century and continues up today [1]. Currently, worldwide annually 800000 artificial hip joints is implanted [2,3,4]. Our knowledge of the body structure and biomaterials, that can be used as artificial part of the human body still increases, the main problem apart from post-operation complications, causing difficulty with implantation of the prosthesis is aseptic loosening by ostheolysis around the implant $[5,6]$. Another problem is incorrect material chosen for the parts of the prosthesis. It can cause severe allergic reactions, that lead to inflammation of the tissues surrounding the implant, or the release of particles of the material, which is used in a joint endoprosthesis. Consequently endoprosthesis should be removed in a subsequent surgery and replaced by the new one [7]. It's important to choose proper geometry. The incorrect defining may lead to loosening of the implant at an early stage after implantation [6]. Moreover, it can later cause damage of patient's natural or artificial joint by generating non-physiological overloads [8]. These mistakes can be minimize by complying with one principle, namely, each patient should be treated individually and before surgery, the geometry of the implant and biomaterial used for its parts should be considered. 
Because we do not have data concerning the 2013, it's necessary to use the existing material from 2012. According to a report of the Polish National Health Fund arthroplasty the number of operations increased over the years, suggesting the growing need of joint replacements and the increasing amount of patients suffering from this problem. As compared to 2005, over 13,000 patients more were operated on Polish hospitals in 2012. The largest group in the statement is presented by 70 - 79 years old woman [9]. This is caused by a greater women bone decalcification [10]. Among all kinds of operations, the main group is the primary joint replacement (36049 operations), but 10\% are revision surgery (3816 operations), and only 640 are a revision surgery without replacement of components [7].

Among the most frequently used metallic biomaterials in orthopaedics: stainless steel, cobalt and titanium alloys are distinguish. The ceramic materials are also very often used: ceramic materials resorbable in the body, materials with controlled surface reactivity and neutral bioceramics [10]. The third group of materials for orthopedic arthroplasty are polymeric materials: natural and synthetic polymers $[10,11]$.

The material implanted in tissues must follow the criteria: good corrosion resistance, suitable mechanical properties, good metallurgical quality and homogeneity, biocompatibility with tissue (non-toxic and not invoking the allergic reactions), abrassion resistance, anti-clotting agent suitable electrical properties and, of course, acceptable manufacturing costs $[12,13,14]$. The most vulnerable human skeletal systems are hip and knee. Their lifetime, depending on the exploitation conditions should be 70 to 90 years long. The synovial fluid existing between the rubbing surfaces in a healthy joint has an excellent friction properties. Unfortunately such a perfect naturally occurring system is not restored by the technique [15].

Most of the endoprosthesis are mass- produced, however the degeneration of healthy joints disturbs their normal geometry. Due to this fact some attempts to personalize the geometry of the implant for the specific case were made. The first step in the selection of the correct geometry is the X-rays or CT of patient's hip analysis [8]. Generally images from Computed Tomography (CT) are used, but it is an expensive procedure( price is much lower [16]) and in medical practice it is not considered necessary for preoperative hip replacement. However, the X-ray joint examinations necessary before the operation. Radiographs obtained during the test are fundamental for the size of the prosthesis estimation [17].

\section{A PARTICULAR CASE}

73 years old patient complained about the pain in the hip. Medical diagnosis revealed degenerative changes in the hip joint (Fig.1).

Degenerative changes are visible, larger in the left hip joint. That's why a total left hip replacement was applied (Fig.2). Visible osteoarthritis was cause of operation [18].

The introduced implant has a head with a diameter of $28 \mathrm{~mm}$ made of Co-Cr-Mo alloy, a stem made of titanium alloy Ti-6Al-4V and covered with hydroxyapatite, the acetabulum with cavities for holder position made of Co-Cr-Mo alloy, coated with hydroxyapatite on the outside and the inside part of the acetabulum was made of polyethylene. 


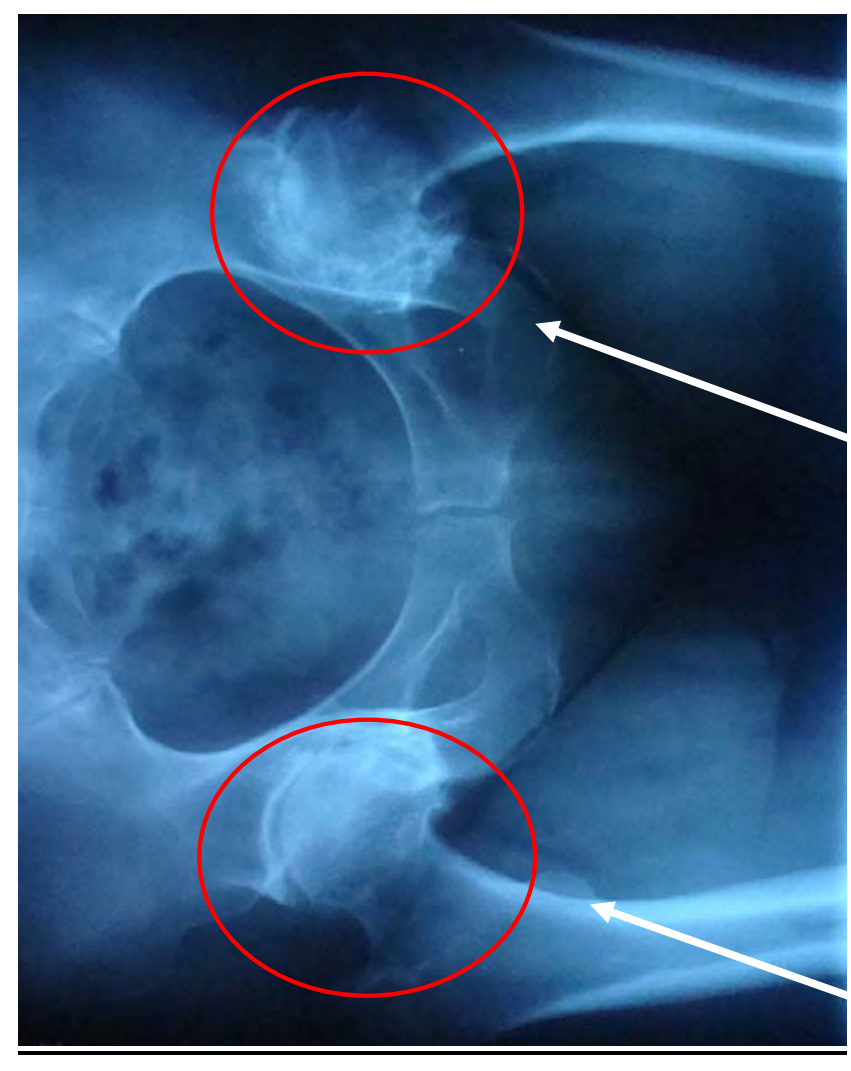

Kenal the joint gap.

The joint gap is not visible.

Within the joint osteofits are visible

Renal the joint gap.

The joint gap is not visible

Fig. 1. Two hip joints with joint's degeneration. The X- ray image [19]

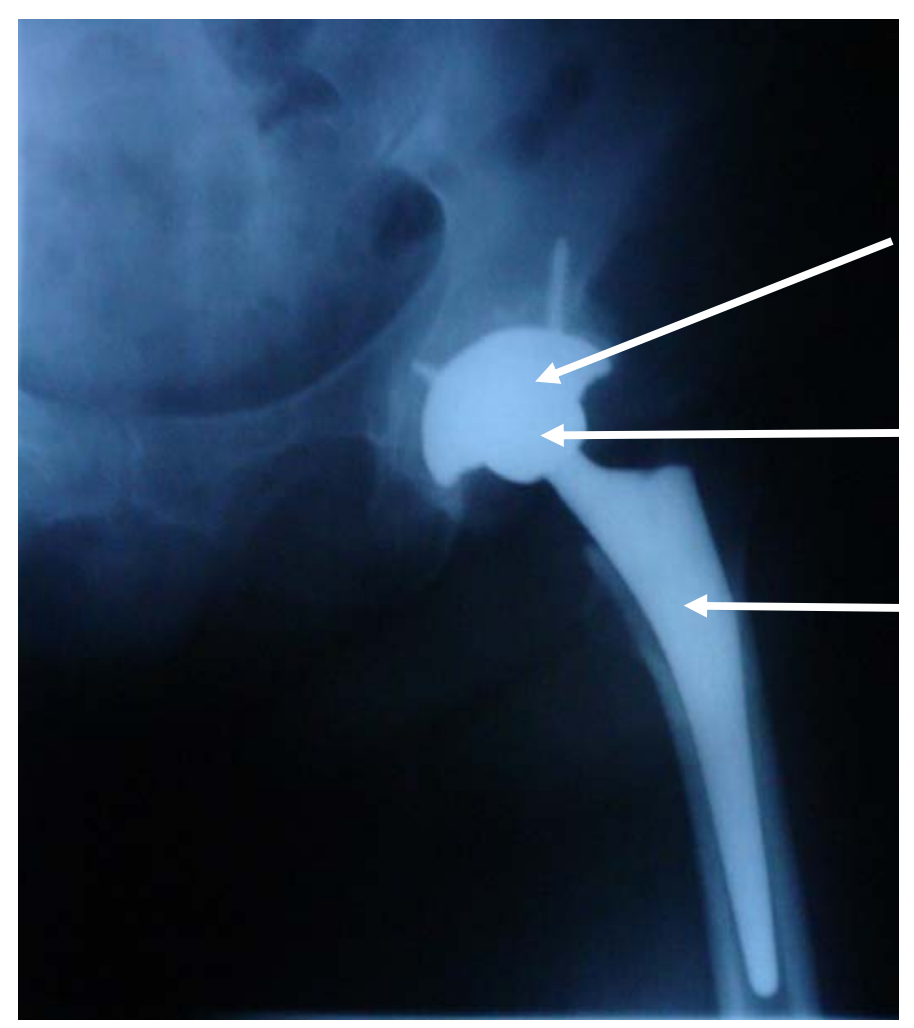

The acetabulum with cavities for holder position

The head

The stem

Fig. 2. Total endoprosthesis of hip joint. The X- ray image 


\section{ENDOPROSTHESIS PROJECT}

Figure 3 shows the geometry of the femoral component of the hip designed for an individual patient. The stem was affected by vertical force $\mathrm{F}$ invoked by the mass of the upper part of the patient's body plus any weight-induced loads affecting implant acting on the implant or the loads caused by other external factors. Because A- A cross- section is the thinnest and the cross- sectional change occurs, it is considered a dangerous cross section and the strength calculations should be performed [20]. The anatomical shape of the endoprosthesis was described by dimensions: the length of the neck (B), opening angle of the stem (C) and the radius of endoprosthesis neck fillet $(\mathrm{C})[8]$.

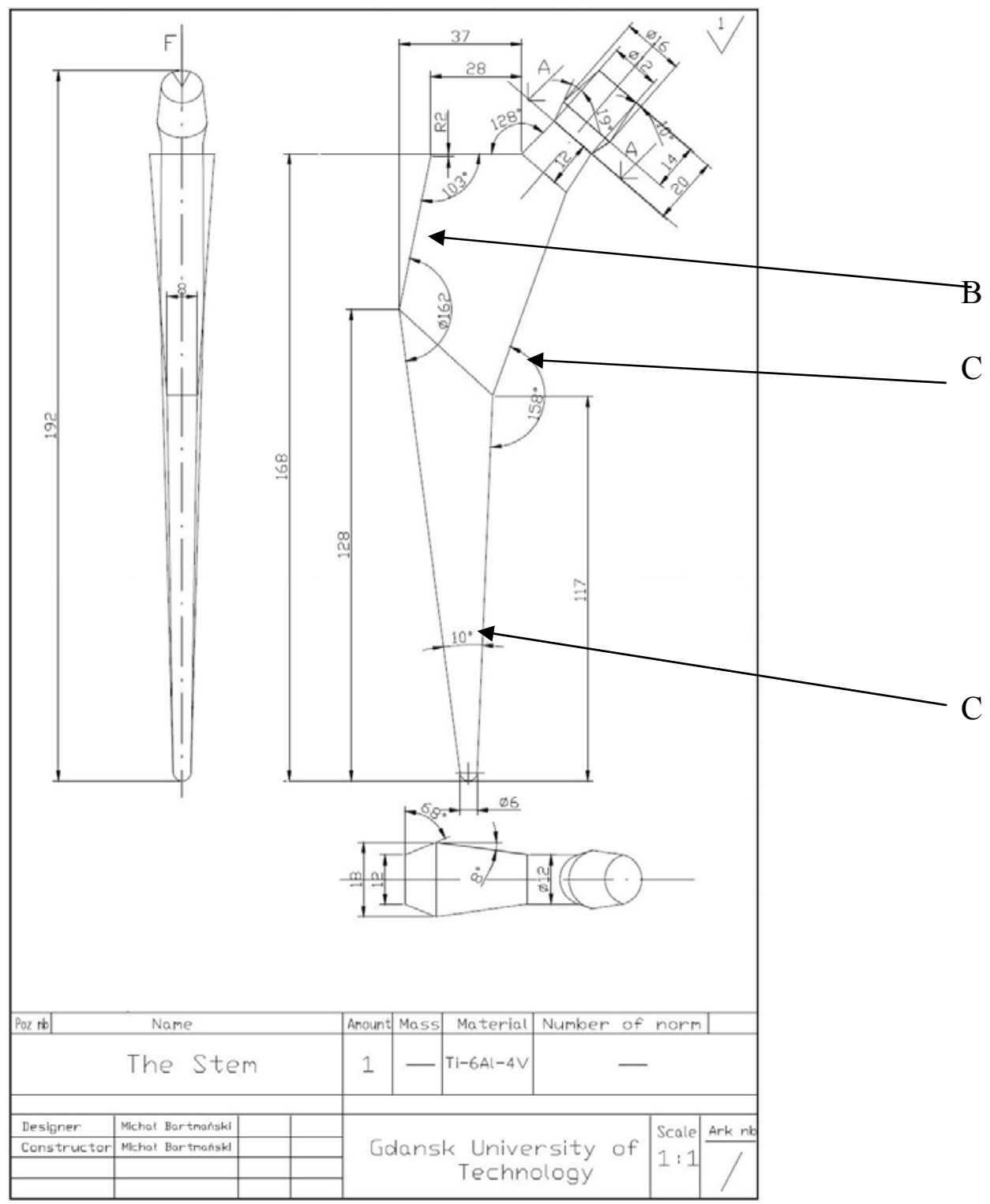

Fig. 3. The hip joint endoprosthesis stem geometric 
To make the calculations we have to simplify the forces system like on the Fig.4.
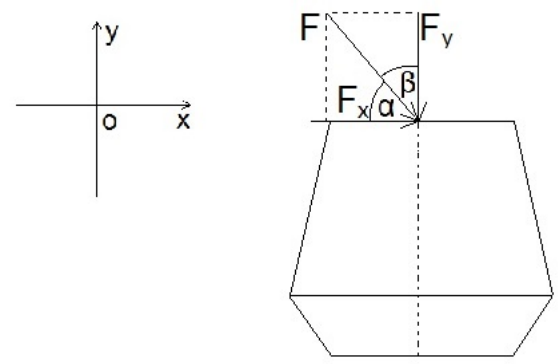

Fig. 4. The forces system. The simplify sketch

To go to the calculations, you should still apply for the cross-section of stress that induce forces Fx and Fy, in order to determine the dangerous places therein are (Fig.5).

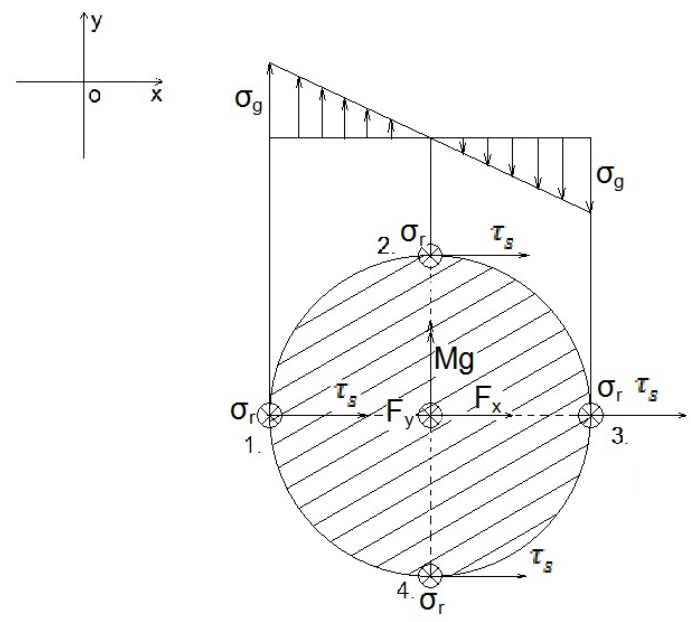

Fig. 5. Distribution of stress-inducing forces Fx and Fy in A- A cross-section

As it can be seen in Fig. 5 the most dangerous place is point 3 and for it stress calculation should be done:

Material: Ti6Al4V

$$
\begin{aligned}
& \mathrm{Rm}=950 \mathrm{MPa} \\
& \mathrm{E}=2.2 * 10^{5} \mathrm{MPa} \\
& \mathrm{Rg}=500 \mathrm{MPa} \\
& \mathrm{X}=1
\end{aligned}
$$

Force:

$$
\mathrm{F}=100 \mathrm{~kg} * 9.81 \mathrm{~m} / \mathrm{s}^{2}=981 \mathrm{~N}(40 \mathrm{~kg} \text { more than [8]) }
$$

Geometric:

$$
\begin{aligned}
& d=12 \mathrm{~mm}=0.012 \mathrm{~m} \\
& \mathrm{a}=20 \mathrm{~mm}=0.02 \mathrm{~m} \\
& \alpha=47^{\circ} \\
& \beta=43^{\circ}
\end{aligned}
$$

Conclusion after calculation: The tested implant is safe. 


\section{DISCUSSION AND CONCLUSIONS}

The hip implant had previously been introduced and up to now, no allergic reactions, complications or other problems associated with the prosthesis have been observed. This statement convinces to choose the same biomaterials as during the first arthroplasty, only the insert of the acetabular prosthesis should be made of $\mathrm{Al}_{2} \mathrm{O}_{3}$ ceramic, because of the point of view of material properties during use are the most durable [6]. During the procedure the high quality, meeting all requirements specified for implants, materials were used.

The head of the prosthesis is made of an Co-Cr-Mo alloy. This alloy is resistant to abrasion and cooperates properly with ceramic acetabular insert. Over the years the use of the alloy is low. An implant made of a particular alloy is mechanically damaged mainly by abrasion, which intensity is mostly determined by factors such as the patient's weight control, physical activity and compliance with the physiotherapist's rules [21].

Stem prosthesis is made of titanium alloy Ti-6Al-4V, which has very good biocompatibility and strength properties. Titanium alloys carry the load properly and are resistant to bending $[11,22]$. Because of the age of the patient, prosthesis is attached with surgical cement [23].

Unfortunately sometimes combinations of two types of materials, in our case Co-Cr-Mo alloy and Ti-6Al-4V alloy, can promotes the formation electrochemical corrosion $[23,24]$.

Acetabulum prosthesis, similarly as a head, should be made of a Co-Cr-Mo alloy. Furthermore the outside of the pan should be coated with hydroxyapatite, which allows the cup to integrate better with the substrate. The press fit connection with bone cement or nails should be used in bearing shell. Bearing- head system is the most vulnerable to tribological destruction part of a total hip endoprosthesis [25]. Therefore a couple of metal (Co-Cr-Mo alloy) - ceramic materials used, due to its good biotribological properties, is a good component of the whole artificial implant. Tribological studies of both materials have confirmed the moderate wear and a small friction factor [23].

The insert to the acetabular prosthesis should be made of $\mathrm{Al}_{2} \mathrm{O}_{3}$ ceramic. Bioceramics materials even after many years of use, degradated slowly, and fulfils its role as an insert to acetabular hip implant for a long time [23].

\section{REFERENCES}

1. Dorr L.D.: Alloplastic of hip joint. Elsevier Urban \& Partner, Wroclaw 2006.

2. Płomiński J., Watral Z.: Testing the stability of the polyethylene acetabulum of an artificial hip joint [in Polish], Diagnostyka, 3 (2006).

3. Kowalczyk E., Sobczyk K.: Examination of time's influence on mechanical properties of polyethylene hip cup endoprosthesis [in Polish], Engineering of Biomaterials, 74 (2008), 11-15.

4. Li S.: Ultra high molecular weight polyethylene: from charney to cross linked, Operative techniques in Orthopedics, 11 (2001), $288-295$.

5. Strzelec - Nowak D., Bogut A.: Microbiological diagnostics of the inflammation of hip joint implants, XXVII meeting of Polish Society of Microbiology in Lublin. 5-8 IX 2012.

6. Semenowicz J., Mroczka A., Kajzer A., Kajzer W., Koczy B., Marciniak J.: Total hip arthroplasty using cementlees Avantage cup in patients with risk of hip prosthesis instability. Orthopedic, Traumatology, Rehabilitation, 16 (3) (2014), 253-263. 
7. Kubacki J.: Alloplastic of hip joints and rehabilitation. The Publishing house of Physical Training Academy. Katowice 2004.

8. John A., Duda M., Kokot G.: The influance of shape endoprosthesis on state of stress and strain of femur, Modelling in engineering ISSN 1896- 771X 44, Gliwice 2012, 117-124.

9. http://www.nfz.gov.pl/new/art/5432/2013_05_07_endoprotezy_2012_analiza.pdf 26.01.2013

10. Głuszko P.: Osteoporosis - prospects for future. Rheumatology, 49 (2011) 372-377.

11. Świeczko-Żurek B.: Biomaterials. The Publishing House of Technical University of Gdansk 2009.

12. Jurczyk M., Jakubowicz J.: Biomaterials. The Publishing House of Technical University of Poznan. Poznan 2008.

13. Niinomi M.: Fatigue characteristics of metallic biomaterials, International Journal of Fatigue, 29 (2007), 992-1000.

14. Bauer S., Schmuki P., von der Mark K.: Engineering biocompatible implant surfaces Part I: Materials and surfaces, Progress in Materials Science, 58 (2013), 261-326.

15. Ryniewicz A.: The analysis of lubrication mechanism of a human hip joint, Monograph no. 111, AGH University of Science and Technology Press, Krakow 2002.

16. http://www.szpitalmsw.pl/mswia/cenniki/cennik_2014_01.pdf 20.12.2014

17. Hallab N.J., Merritt K., Jacobs J.J.: Metal sensitivity in patients with orthopedic implants. J. Bone Joint Surg. Am., 83-A (2001), 428-436.

18. Leszczyński P., Pawlak - Buś K.: Osteoarthritis - the epidemic of the 21th century, Contemporary Pharmacy, 1 (2008), 78-87.

19. Door L. D.: Hip Arthroplasty, Elsevier Urban and Partners, Wroclaw 2009.

20. Niezgodziński M. Niezgodziński T.: Strenght of Materials, Polish Scientific Publishers PWN, Warszawa 2009.

21. Szarek A.: The assessment of wear of metal heads in hip joint prosthesis removed from human body due to aseptic loosening [in Polish], Inżynieria Biomateriałów, 74 (2008), 6-10.

22. Szewczenko J., Pochrząst M., Walke W.: Evaluation of electrochemical properties of modified Ti-6Al-4V ELI alloy, Electrical Review, 12b (2011), 178-181.

23. Kajzer A., Kajzer W., Semenowicz J., Mroczka A.: Corrosion resistance of hip endoprosthesis cups in the initial state and after implantation. Solid State Phenomena, 227 (2015) 523-526.

24. Przondziono J., Walke W., Hadasik E, Szymszal J.: The effect of strain hardening on resistance to electrochemical corrosion of wires for orthopedics. Technologies and Properties of Modern Utilised Materials. IOP Conference Series: Materials Science and Engineering, 35, 012015, 2012, $1-9$.

25. Gierzyńska-Dolna M.: Biotribology and medical application, Tribology 4, 2003. 